\title{
Climate Insurance for the Poor: Challenges for Targeting and Participation
}

\author{
Rachele Pierro and Bina Desai
}

\begin{abstract}
1 Introduction: why insurance?
A growing body of evidence indicates that climate change is set to increase the frequency and intensity of natural hazards (IPCC 2007). A recent United Nations report (2007) asserts that global hydrometeorological hazards, such as droughts, floods and hurricanes, have increased by 87 per cent over the last 20 years. Those most affected by this trend are the world's poor. Poor people in developing countries are the most exposed to natural hazards, as in most cases they have to manage weather risks by their own means and have limited or no access to insurance and financial services to help them recover from crises (Syroka and Wilcox 2006).
\end{abstract}

In sub-Saharan Africa about 140 million people live with the constant threat of droughts or floods. Prevailing uncertainty and the absence of financial safety nets makes it difficult for poor farmers to make higher-risk, higher-return investments. Then, when the rains fail, vulnerable households act fast. Immediate response strategies include selling nonproductive assets or migration of family members. However, if the situation does not improve, they are forced to use more costly coping strategies, like removing children from school, reducing food consumption and health expenditures, and selling productive assets, such as farming tools and livestock (Barnett et al. 2006; Hess et al. 2006).

By the time humanitarian aid reaches the poor, the majority have already lost key assets and livelihoods, and therefore their ability to benefit from better weather the following year (WFP 2006). According to the World Bank and the World Food Programme (WFP) this response 'delay' under an ex post emergency model, accounts for large numbers of new destitute people after a climate-related disaster. After losing their productive assets, these newly poor are often trapped in a state of dependency on external aid for many years (Hess et al. 2006; Morris 2005), and risk moving from temporary poverty to being chronically poor.

In this scenario, humanitarian assumptions have started to be questioned: are our response mechanisms working or will the reinforcement of old practices become a risk for the poor? Do we need to find a more effective and sustainable way to approach weather risk and humanitarian assistance? In response to these questions, innovative models are now being considered and tested (Pelling 2007).

This article looks at weather insurance schemes recently piloted at the micro- and macro-levels, and assesses their potential as tools for social protection. It highlights the challenges of and differences between the two approaches, and looks at the opportunities for improved targeting and local participation.

Key findings are that weather-based microinsurance ultimately targets relatively better off farmers and is not an appropriate tool for broad social protection targeting all poor groups. Macroinsurance policies in support of existing social protection programmes appear to have more potential in reaching the most vulnerable. By providing timely and predictable aid after a severe drought, disaster insurance can have an important role in saving the livelihoods of transiently food-insecure people. ${ }^{1}$

2 Is traditional crop insurance a viable option? In developed countries, traditional multi-peril crop insurance is widely used and heavily subsidised by the 
government. However, many have questioned the financial viability of such schemes (Skees et al. 1999), considering not only the high monitoring and administrative costs, but also the risk of adverse selection and moral hazard; since once insured, farmers often lose the incentive to minimise their loss by investing in risk reduction. Therefore, traditional crop insurance has been seen as a poor model for export, particularly for developing countries, most of which are under serious fiscal constraints and have smallholder economies highly exposed to the risk of simultaneous losses from a single event (Morduch 2001).

Recently, due to the introduction of a new approach to crop insurance with index-based products, an opportunity for improving vulnerable communities' resilience has arisen: through close integration of disaster risk reduction with risk transfer tools there is a chance to create a viable insurance market in developing countries and to provide a mechanism for financing safety net and disaster relief programmes in countries where climate variability constitutes a major risk (Pelling 2007; Barnett et al. 2006).

\section{Index-based risk transfer products}

Index-based insurance is still a relatively new tool and more research is necessary to fully comprehend its potential and limitations. Unlike traditional insurance, contracts are written on a physical trigger (i.e. rainfall measurements at a local weather station) that acts as a proxy for crop losses a farmer experiences in his field, rather than using his actual losses to determine a claim. Since no field inspections are required, there is a drastic reduction of transaction costs and claims can be paid promptly. Moreover, as the index is based on objectively measurable data, there are few asymmetric information problems and the index can be transferred directly to international financial markets (Morris 2005; Mechler et al. 2006; Davies et al., this IDS Bulletin).

The drawback is that significant investments in the start-up phase are necessary to develop these schemes, and international reinsurance companies may be reluctant to cover these costs. Therefore, some aid agencies and governmental organisations have started piloting these schemes to explore their potential.

Index-based schemes can be implemented at microor macro-level. The micro-model offers protection to weather risks that have direct impact on a farmer's agricultural production. The macro-model focuses on risk at an aggregate level and when crop production is affected at a regional, national or multi-country level. Usually, these initiatives aim to meet different policy objectives and target different segments of the rural population with different risk profiles than the micro-models. Both models pose different challenges with regard to local participation and targeting.

\section{$4 \mathrm{~A}$ micro approach to index-based insurance} To date, only a few micro-level policies have been implemented. ${ }^{2}$ These models require a big initial investment for the start-up phase, primarily to collect the necessary data to establish the index, but can become self-sustainable when the project scales up and a big pool of insured people (generally more than $10,000)$ is created. ${ }^{3}$ These micro policies can be sold to individual farmers or to groups, like a cooperative or an entire village, and can also offer protection for localised weather risks (Mechler et al. 2006).

As highlighted at the 2007 ProVention Forum, major challenges to this approach are the threat that large covariant losses can pose to the financial stability of insurers and the prevailing absence of an institutional architecture to pull risk transfer and risk reduction together (Pelling 2007). One of the key lessons learnt to date is that investment in microinsurance without complementary investment in financial intermediaries and effective marketing channels and supply chains, where linkages can be made, will limit the take-up and scalability of such initiatives (UN DESA 2007).

In fact, as the Malawi experience highlights (see Box 1), in order for this insurance to work, other risks faced by farmers (such as access to market and to credit) need to be addressed. Moreover, to date, the most financially sustainable examples of weather microinsurance have been where insurance is offered as part of a broader portfolio of policies (as done in the BASIX scheme). Technical issues can represent another limitation. Since this type of insurance has to capture local weather events on a farmer's field, a large number of weather stations are necessary.

These characteristics of micro policies pose significant challenges for the targeting of areas and communities where services like market, insurance providers and diffused weather stations are absent and, for different reasons, difficult to develop. 


\section{Box 1 NASFAM in Malawi}

Small-scale peanut farmers in Malawi are generally unable to buy high-quality seeds that are more resistant to drought on a regular basis. In 2005, to make them more creditworthy, NASFAM (a farmers' association) with technical assistance from the World Bank and Opportunity International, designed a pilot index-based insurance scheme. Multiple underwriters were necessary since no single underwriter was willing to take the risk alone, given the huge payout in the event of a drought. In the first season, 892 farmers bought the insurance; they were small farmers with an average of one acre of land (Opportunity International 2005).

However, farmers experienced a low harvest due to the seed quality they received. The seeds provided by NASFAM were too old, producing poor yields and resulting in an inability by participating farmers to repay their loans. ${ }^{4}$ This experience shows that microinsurance can be a tool in disaster mitigation only if the coupled services are functioning well.

\subsection{Targeting and participation}

In principle, this model is able to offer protection to different categories of the poor (not only farmers but also landless and pastoralist communities), making it potentially more relevant than traditional crop insurance. The index-based approach at the micro-level also suggests a higher degree of transparency and can limit corruption. $A$ key requisite for transparency and accountability of these schemes however, is a community's active involvement in managing the insurance, as it will directly determine the levels of responsibility the community is willing to assume for the success or failure of the scheme (Pierro and Desai 2007).

However, a major challenge is the affordability of commercial insurance for the poor (Pelling 2007). Experience from Malawi and India suggests that micro weather insurance may not be an appropriate solution for very poor rural communities and for the poorest parts of the population. In fact, staff from World Bank involved in developing such schemes point out that these products focus on increasing the productivity and profitability of less poor farmers, which is why they are often bundled with credit and input supplies. ${ }^{5}$

Basis risk (that occurs when the trigger is insufficiently correlated with the losses and no payout is given even though losses occurred), combined with 'perceived' basis risk can make this tool unsuitable for the poorest. People for which the payment of a premium can already be a heavy burden, could lose any incentive after experiencing a loss that is not covered by the policy (for instance crop loss due to pest attack). They could perceive the insurance as a fraud and decide not to renew the policy for the future. Only people with some assets to protect and certain levels of financial liquidity will be able and willing to pay the premium on a regular basis. These limitations are likely to determine difficulties in targeting subsistence farmers who face multiple risks, and make this tool inappropriate for social protection.

There is still a lack of information on what is necessary for the poor to fully benefit from this tool. According to Christian Aid programme staff for instance, the presence of empowered communities and the absence of conflict are crucial conditions (Pierro and Desai 2007). Additional factors are an affordable premium, the simplicity of the scheme and broad coverage. However, local culture could strongly interfere with the viability of these schemes and the willingness of people to pay for the premium: lack of trust in top-down interventions and a lack of incentives, resources and energy can present significant barriers.

Understanding the poor's expectations of benefits from the insurance, and building their trust through improved transparency of the scheme will be crucial for its success. Certainly, more research and pilot studies are necessary to explore how this tool can affect power relations within a village, including the effects it may have on people unable to join the scheme and on gender relations within a household. ${ }^{6}$

\section{A macro approach to index-based insurance}

A different approach to index-based insurance is currently being piloted at the macro-level, through national and multi-country policies. These schemes 
Table 1 Some advantages and challenges of disaster insurance

\begin{tabular}{|c|c|}
\hline Advantages of disaster insurance & Challenges and limitations of disaster insurance \\
\hline $\begin{array}{l}\text { - It can increase governments' self-determination } \\
\text { and ownership } \\
\text { - It could save livelihoods, therefore it can be more } \\
\text { financially sustainable than traditional humanitarian } \\
\text { aid, which focuses on saving lives } \\
\text { - By guaranteeing a predictable and reliable payout } \\
\text { in case of disaster, it will allow for longer-term } \\
\text { planning in development } \\
\text { - It can diminish the negative effect external relief } \\
\text { and reconstruction interventions often have in } \\
\text { eroding local markets and exacerbating social } \\
\text { inequalities (Pelling } 2007 \text { ) } \\
\text { - It seems transferable to other countries with } \\
\text { available historical and up-to-date weather data. } \\
\text { The World Bank is also exploring the opportunity } \\
\text { for using Satellite Imaging } \\
\text { - It will create or reinforce the idea that the state } \\
\text { has responsibilities to ensure its citizens' safety and } \\
\text { protection of their livelihoods (Pelling } 2007 \text { ) } \\
\text { - It can guarantee greater dignity for the } \\
\text { beneficiaries than aid appeals (Syroka and Wilcox 2006) } \\
\text { - If weather data collected are openly shared, they } \\
\text { can be valuable for any disaster risk reduction } \\
\text { programme } \\
\text { - It could offer a basis for a rights-based approach } \\
\text { to climate change }\end{array}$ & $\begin{array}{l}\text { - Payment of premium can be unsustainable for } \\
\text { governments and donors } \\
\text { - Difficulty of engagement with civil society, as } \\
\text { already experienced by the implementation of the } \\
\text { PSNP } \\
\text { - Risk of conflict with existing response capacities, } \\
\text { where they can overlap with new programmes } \\
\text { complementing the insurance (see possible conflict } \\
\text { between Disaster Prevention and Preparedness } \\
\text { Committee (DPPC) and Contingency Plan in Ethiopia) } \\
\text { - It needs to be part of a broader contingency plan, } \\
\text { since it can only cover catastrophic risk (not small-scale } \\
\text { disasters) } \\
\text { - It is not capable of addressing all types of } \\
\text { humanitarian crisis (e.g. conflicts). Therefore, as a social } \\
\text { protection tool, it needs to be part of a broader set of } \\
\text { emergency response mechanisms (Barnett et al. 2006) } \\
\text { - It can replace losses but cannot be a substitute for } \\
\text { job creation, for market access, or education that did } \\
\text { not exist in the first place } \\
\text { - Complexity of cost-benefit analysis }\end{array}$ \\
\hline
\end{tabular}

appear to be suitable for low-probability, highconsequence weather risks.

The first National Disaster Insurance was implemented in Ethiopia in 2006 while the first Multi-country Disaster Insurance was implemented in the Caribbean in 2007. In these policies, the contract is written between governments, donors and a reinsurance company. This policy would guarantee national governments a reliable payout as soon as an insured disaster strikes. The World Bank, WFP and Department for International Development (DFID) have been involved in its promotion and pilot, helping national stakeholders to build capacity that would enable them to link with international financial markets.

Macroinsurance is easier to implement than microinsurance, since it involves only few insured entities (governments and development agencies), which can deal with basis risk more easily than individual farmers can. Covering only severe weather events, it does not require as large a number of weather stations to be implemented successfully as microinsurance (only about 26 weather stations were sufficient to cover the whole of Ethiopia).

Moreover, disaster insurance, seen as a national adaptive mechanism to climate change, could offer the basis for a rights-based approach to climate change. For instance, models could be developed where subsidies to the insurance's premium would be provided by high carbon-producing countries as part of compensatory schemes for adaptation in countries affected by climate change; managed through the UN Framework Convention on Climate Change's (UNFCCC) Adaptation Fund.

During the 2007 ProVention Forum, some key challenges have been identified for this macro approach: financial sustainability of insurance products, creating incentives for risk reduction, and difficulty in 


\section{Drought insurance in Ethiopia}

In Ethiopia, the emergency system recently underwent a major reform. Starting in 2005, the government introduced the Productive Safety Net Programme (PSNP), a predictable and increasingly cash-based model targeting the chronically food-insecure. However, this partial reform of the emergency system did not appear to be financially sustainable, since it did not include an effective mechanism to protect livelihoods of the transiently food-insecure people. They remained at risk of losing their assets during future crises, risking an unsustainable growth of the chronically foodinsecure community and therefore the PSNP.

Then in 2006, the first National Disaster Insurance was piloted by the WFP and AXA Re. in Ethiopia, targeting the transiently food-insecure community (Hess et al. 2006). While the pilot provides only a small amount of contingency funding, covering 310,000 beneficiaries with a maximum payout of $\$ 7.1$ million, the model is calibrated to potentially assist 17 million Ethiopian farmers who risk destitution as a consequence of a severe drought (Syroka and Wilcox 2006). The insurance will be part of an Early Livelihood Protection Facility, combining a Contingency Fund (up to $\$ 50$ million) for very mild droughts, an additional Contingency Grant (up to $\$ 40$ million) for mild droughts and additional Disaster Insurance provision (up to $\$ 60$ million) for severe droughts (Hess et al. 2006).

finding a balance of public-private roles. Additionally, there is the technical challenge of generating reliable historical and updated meteorological data while developing effective climate change scenarios to use as the basis for estimating future risk (Table 1).

The aim of currently tested macro-level schemes, such as the Ethiopia pilot, are to explore whether it is feasible to use market tools to finance drought risk, and to prove that accurate indicators can be developed to trigger drought assistance. While in that respect the Ethiopia pilot appears to have been successful, key challenges for its implementation remain targeting and participation.

\subsection{Targeting and participation}

A study carried out on the Ethiopia Productive Safety Net Programme (PSNP) shows that overall, the programme reaches the poor and food-insecure but that the level of transparency and accountability varied greatly across the region. Several problems have been highlighted, for instance bad timing of public work in some areas, overlapping of membership of the targeting and appeals bodies and some gender issues (Sharp et al. 2006). According to Christian Aid staff, the top-down approach of these national programmes is creating conflict with local civil society. Local non-governmental organisations (NGOs) are not involved in the identification and planning of public work projects and the large scale of these projects often undermines the viabilities of smaller local projects. ${ }^{8}$
For the disaster insurance scheme, the WFP and the Government of Ethiopia's Food Security Bureau designed an Implementation Rulebook, modelled on and complementary to the PSNP, describing targeting guidelines for cash-for-work or food-for-work projects (Hess et al. 2006, WFP 2006). The combination of community-based and administrative targeting systems laid out in the rulebook should help to ensure a certain degree of community participation and ownership. However, to date there is no information about participation levels and targeting outcomes in the Ethiopia insurance scheme as it has only been piloted once and no payout has occurred to date.

From the Ethiopia pilot, it emerges that for drought insurance to be affordable, can only cover catastrophic droughts and needs to be coordinated with a safety net programme (like the PSNP), targeting people exposed also to chronic risk. But drought insurance can enhance and increase the sustainability of social protection systems that aim to reach the poorest during emergencies. More research is required to better understand the different opportunities for disaster insurance in covering other weather risks besides droughts and in targeting people with different levels of vulnerability.

\section{Conclusions}

Index-based weather insurance is still at a pilot stage and many questions remain unanswered. More research and comparison among different projects is required to understand the feasibility of this approach, 
its financial sustainability and the different options for its implementation. What can be said with some clarity, however, is that local participation at every stage of an insurance programme's design, implementation and monitoring remains a key challenge and yet is crucial to its success. To build on existing experience and further explore the potential of weather insurance, stakeholders at all levels need to get involved.

Civil society and the private sector must use their skills, expertise and institutional structures to work alongside governments. Risk transfer programmes need to be piloted and tested in their ability to become an integral component of countries' broader strategies to reduce the devastating consequences of natural disasters.

From the evidence reviewed for this article, as tools for social protection, macroinsurance models have more potential than microinsurance schemes. Therefore, the following final conclusions focus on what is needed to advance our understanding of the potential role of national and regional disaster insurance schemes for disaster risk reduction and climate change adaptation.

1 More research is required to critically analyse current experience and develop solid feasibility studies.

(a) Which disasters can be covered by index-based insurance? ${ }^{9}$

(b) What are the first steps in developing appropriate models and who should bear the high cost of start-up phases?

(c) What are the qualitative impacts of this model? How can it impact on the protection of livelihood? How does it impact on women's access to public space and on poor people's access to markets and social services?

(d) In the Ethiopia pilot, the insurance is part of an Early Livelihood Protection Facility. Is this complex structure transferable to other pilots? What are other options?

(e) In Ethiopia and in the Caribbean, premiums for pilot Disaster Insurance are paid by governments

\section{Notes}

1 Transiently food-insecure people can be defined as people who, even though normally foodsecure, are subject to acute but temporary food shortages due to climatic or other sudden shock. and donors. Who can be expected to pay for the premium in the long term? Is such an annual disbursement ( $\$ 5$ million has been estimated by the World Bank as the necessary annual premium to cover 1.5 million people in Ethiopia from severe droughts) a feasible approach to emergency management?

(f) Can a rights-based approach to Disaster Insurance be developed at an international level? What are the options for this in the context of climate change adaptation and the current UNFCCC negotiations?

2 Participation issues need to be addressed and engagement with civil society must be improved.

(a) What is the present experience with transparency and local participation in disaster insurance? How can it be documented more systematically and built on more effectively?

(b) Given the problems with the PSNP in Ethiopia highlighted by Christian Aid staff, how can communities and civil society become more involved?

(c) There is a need to understand power relations at the local level in order to have real participation and in order to avoid reinforcing social inequalities. These questions need to be considered: Who are the stakeholders involved in the process? Which are the power relations present among them? Has voice been given to all stakeholders involved?

3 The Ethiopia pilot showed that drought insurance targets transiently food-insecure people and can therefore protect the PSNP.

(a) Is that the case also with other disaster insurance? Or can this tool in other contexts directly target the most vulnerable parts of the population?

(b) How was the targeting process carried out in present experiences? How has it been monitored?

(c) What was the level of participation in the targeting process?

(d) Whose risks and which risks are really being transferred?

2 For example the BASIX pilot in India (see www. basixindia.com) and NASFAM's scheme in Malawi (Box 1).

3 Personal communication with Opportunity International's staff, March 2007. 
4 World Bank website: www.worldbank.org

5 Personal communication with Joanna Syroka, World Bank, 17 August 2007.

6 The ProVention Consortium has recently started a joint evaluation of ten microinsurance pilot schemes in Asia. The study focuses on financial viability, on the schemes' contribution to risk reduction and on the impact on insurers' households. It will certainly give an important contribution towards a better understanding of

\section{References}

Barnett, B.J.; Barrett, C.B. and Skees, J.R. (2006) Poverty Traps and Index Based Risk Transfer Products, http://aem.cornell.edu/faculty_sites/cbb2/Papers/ Poverty\%20Traps\%20and\%2OIndex\%20Based\%20 Risk\%20Transfer\%20Products\%202nd\%20Round\% 20Submission.pdf (accessed 3 June 2008)

Hess, U.; Wiseman, W. and Robertson, T. (2006) Ethiopia Integrated Risk Financing to Protect Livelihoods and Foster Development, Discussion Paper, Addis Ababa: WFP/WB/DFID

IPCC (2007) Climate Change 2007: Synthesis Report, R.K. Pachauri and A. Reisinger (eds), Geneva: Intergovernmental Panel on Climate Change

Mechler, R.; Linnerooth-Bayer, J. and Peppiatt, D. (2006) Disaster Insurance for the Poor? A Review of Microinsurance for Natural Disaster Risks in Developing Countries, Geneva: ProVention Consortium and Laxenburg: International Institute for Applied Systems Analysis (IIASA)

Morduch, J. (2001) Rainfall Insurance and Vulnerability: Economic Principles and Cautionary Notes, Working Paper, New York: New York University

Morris, J. (2005) 'Can Insurance Break Ethiopia's Vicious Cycle of Hunger', Financial Times, 10 May

Opportunity International (2005) Weather Index Insurance, Malawi, www.microinsurancecenter.org/ resources/Documents/051101\%20Drought\%20ins urance\%200pportunity\%20International.pdf (accessed 2 June 2008)

Pelling, M. (2007) Making Disaster Risk Reduction Work, a review and discussion of key themes, challenges and potential contributions to be made by ProVention in promoting disaster risk reduction. The 2007 Provention Forum, Dar es Salaam, Tanzania, April 2007. ProVention Consortium/IFRC, www.proventionconsortium.org/ themes/default/pdfs/Forum_2007_report.pdf (accessed 6 August 2008) microinsurance's ability to reduce risks for people with different level of vulnerability.

$7 \mathrm{UN} \mathrm{OCHA} \mathrm{(2007)} \mathrm{Evaluation} \mathrm{of} \mathrm{the} \mathrm{Response} \mathrm{to} \mathrm{the}$ 2002-03 Emergency in Ethiopia.

8 Personal communication with Christian Aid's Ethiopia country manager, 18 July 2007.

9 For instance the Commodity Risk Management Group is testing flood index insurance in Vietnam, based on satellite imaging.

Pierro, R. and Desai, B. (2007) Micro-insurance and DRR: Challenges and Opportunities in the Context of Climate Change, internal paper, London: Christian Aid

Sharp, K.; Brown, T. and Teshome, A. (2006) Targeting Ethiopia's Productive Safety Net Programme (PSNP), London: Overseas Development Institute and Bristol: the IDL Group

Skees, J.; Hazell, P. and Miranda, M. (1999) New Approaches to Crop Yield Insurance in Developing Countries, Discussion Paper 55, Washington DC: International Food and Policy Research Institute, Environment and Production Technology Division

Syroka, J. and Wilcox, R. (2006) 'Rethinking International Disaster Aid Finance', Journal of International Affairs 59.2: 197-215

UN DESA (2007) Developing Index-based Insurance for Agriculture in Developing Countries, Sustainable Development Innovation Briefs 2, March 2007, www.un.org/esa/sustdev/publications/ innovationbriefs/no2.pdf (accessed 6 August 2008)

UN OCHA (2007) Evaluation of the Response to the 2002-03 Emergency in Ethiopia, Steering Committee for the Evaluation of the Joint Government and Humanitarian Partners Response to the 2002-03 Emergency in Ethiopia, October 2004. www. ocha-eth.org/ Reports/downloadable/Thematics2004/Eval_ ReportOctober2004.pdf (accessed 6 August 2008)

United Nations (2007) International Cooperation on Humanitarian Assistance in the Field of Natural Disasters, from Relief to Development, New York: The Secretary-General, United Nations

WFP (2006) Ethiopia Drought Insurance Update and 2007 Weather Risk Management Work Plan, World Food Programme Operational Report, www.wfp.org/eb/docs/2006/wfp105616 1.pdf (accessed 3 June 2008) 